\title{
IMPLEMENTASI KEBIJAKAN PEMENUHAN HAK ORANG DENGAN GANGGUAN JIWA DI KABUPATEN HULU SUNGAI UTARA
}

\author{
RENO AFFRIAN \\ Sekolah Tinggi Ilmu Administrasi (STIA) Amuntai \\ renoaffrian@gmail.com
}

\begin{abstract}
ABSTRAK
Mental disorders are a collection of abnormal conditions, both those related to physical and mental. Local governments are responsible for fulfilling the rights of people with mental disorders, the right to get treatment and care and rehabilitation in order to obtain complete recovery.

Based on the results of the research that has been carried out it can be concluded that: Implementation of the fulfillment of the rights of people with mental disorders has not fully gone well, it is seen from the resources to run mental health services are not fully adequate, and there are still problems related to the economic, social and political. Factors that influence the Implementation of the Fulfillment of the Rights of People with Mental Disorders in Hulu Sungai Utara Regency are influenced by several factors 1. Resources 2. Economic, Social and Political Environment
\end{abstract}

Keywords : implementation, right, mental disorders

\section{LATAR BELAKANG}

Undang-Undang Dasar Negara Republik Indonesia Tahun 1945 pasal 28I ayat (4) mengamantkan "perlindungan, pemajuan, penegakan dan pemenuhan hak asasi manusia adalah tanggungjawab negara, terutama pemerintah". Dengan demikian maka pemerintah melindungi agar hak asasi seseorang tidak dilanggar oleh orang lain.

Gangguan jiwa adalah kumpulan dari keadaan-keadaan yang tidak normal, baik yang berhubungan dengan fisik maupun mental" Penderita gangguan jiwa termasuk kedalam kartegori cacat mental, sesuai dengan pernyataan tersebut maka penderita gangguan jiwa dijamin haknya untuk mendapat perawatan dan bantuan khusus atas biaya Negara untuk menjamin kehidupan yang layak sesuai dengan martabat kemanusiaanya. Hal tersebut didukung pula oleh Undang-undang Republik Indonesia Nomor 36 Tahun 2009 tentang Kesehatan Pasal 147 dan 149 menyatakan bahwa Pasal 147 (1) Upaya 
penyembuhan penderita gangguan kesehatan jiwa merupakan tanggung jawab Pemerintah, pemerintah daerah dan masyarakat. (2) Upaya penyembuhan sebagaimana dimaksud pada ayat (1) dilakukan oleh tenaga kesehatan yang berwenang dan di tempat yang tepat dengan tetap menghormati hak asasi penderita. (3) Untuk merawat penderita gangguan kesehatan jiwa, digunakan fasilitas pelayanan kesehatan khusus yang memenuhi syarat dan yang sesuai dengan ketentuan peraturan perundang-undangan. ayat (2) yang menyatakan bahwa "pemerintah, pemerintah daerah dan masyarakat wajib melakukan pengobatan dan perawatan difasilitas pelayanan kesehatan bagi penderita gangguan jiwa yang terlantar, menggelandang, mengancam keselamatan dirinya dan/atau orang lain, dan/atau mengganggu ketertiban dan/atau keamanan umum”.

Landasan hukum terkait pemenuhan hak penderita gangguan jiwa juga terdapat pada Undang-Undang Republik Indonesia Nomor 18 Tahun 2014 Tentang Kesehatan Jiwa yang memperkuat pernyataan yang ada pada Undang-undang Republik Indonesia Nomor 36 Tahun 2009 Pasal 149 ayat (2).

\section{Undang-Undang} Republik Indonesia Nomor 18 Tahun 2014 Tentang
Kesehatan Jiwa Pasal 81 menyatakan bahwa

1. Pemerintah dan Pemerintah Daerah wajib melakukan upaya rehabilitasi terhadap ODGJ terlantar, menggelandang, mengancam keselamatan dirinya dan/atau orang lain, dan/atau mengganggu ketertiban dan/atau keamanan umum.

2. ODGJ terlantar, menggelandang, mengancam keselamatan dirinya dan/atau orang lain, dan/atau mengganggu ketertiban dan/atau keamanan umum sebagaimana dimaksud pada ayat (1) meliputi ODGJ:

a. tidak mampu;

b. tidak mempunyai keluarga waliatau pengampu; dan/atau

c. tidak diketahui keluarganya

Dengan adanya pasal-pasal yang telah disebutkan dengan jelas sebelumnya maka dapat disimpulkan bahwa pemerintah daerah bertanggung jawab atas pemenuhan hak penderita gangguan jiwa, hak yang dimaksud tersebut adalah hak untuk mendapatkan pengobatan dan perawatan serta rehabilitasi guna memperoleh kesembuhan seutuhnya agar mereka dapat menjadi manusia produktif secara sosial dan ekonomis. Rehabilitasi yang dilakukan untuk kesembuhan penderita ganguan jiwa adalah rehabilitasi sosial. 
Kabupaten Hulu Sungai Utara merupakan

Kabupaten yang memiliki masalah orang dengan ganggun jiwa kasus dirantai dan dipasung cukup tinggi. berikut data sebaran penderita gangguan jiwa dikabupaten Hulu Sungai Utara :

Tabel 01

\section{Daftar Sebaran Orang Dengan}

Gangguan Jiwa

Kabupaten Hulu Sungai Utara tahun 2018

\begin{tabular}{|c|c|c|c|c|}
\hline No & Nama & Alamat & Wilayah & $\begin{array}{l}\text { Keterang } \\
\text { an }\end{array}$ \\
\hline 1 & Salah & $\begin{array}{l}\text { Desa } \\
\text { Pulau } \\
\text { Damar }\end{array}$ & Banjang & Dirantai \\
\hline 2 & Aluh & $\begin{array}{l}\text { Desa } \\
\text { Teluk } \\
\text { Lombung }\end{array}$ & Babirik & Dikurung \\
\hline 3 & $\begin{array}{l}\text { Ny. } \\
\text { Aida }\end{array}$ & $\begin{array}{l}\text { Desa } \\
\text { Teluk } \\
\text { Lombung }\end{array}$ & Babirik & Dikurung \\
\hline 4 & $\begin{array}{l}\text { Ny. } \quad \mathrm{Hj} \\
\text { Kasiah }\end{array}$ & $\begin{array}{l}\text { Desa } \\
\text { Murung } \\
\text { Panti } \\
\text { Hilir } \\
\end{array}$ & Babirik & \\
\hline 5 & Dikan & $\begin{array}{l}\text { Desa } \\
\text { Sungai } \\
\text { Namang }\end{array}$ & $\begin{array}{l}\text { Danau } \\
\text { Panggang }\end{array}$ & Dikurung \\
\hline 6 & $\begin{array}{l}\text { Muham } \\
\text { mad }\end{array}$ & $\begin{array}{l}\text { Desa } \\
\text { Palukaha } \\
\mathrm{n}\end{array}$ & $\begin{array}{l}\text { Danau } \\
\text { Panggang }\end{array}$ & Dikurung \\
\hline 7 & M. Ali & $\begin{array}{l}\text { Darussala } \\
\mathrm{m}\end{array}$ & $\begin{array}{l}\text { Danau } \\
\text { Panggang }\end{array}$ & Dikurung \\
\hline 8 & $\begin{array}{l}\text { Hasanud } \\
\text { din }\end{array}$ & $\begin{array}{l}\text { Danau } \\
\text { Panggang }\end{array}$ & $\begin{array}{l}\text { Danau } \\
\text { Panggang }\end{array}$ & Dirantai \\
\hline 9 & $\begin{array}{l}\text { M. } \\
\text { Makki }\end{array}$ & $\begin{array}{l}\text { Desa } \\
\text { Jinggah } \\
\text { Bujur } \\
\end{array}$ & $\begin{array}{l}\text { Haur } \\
\text { Gading }\end{array}$ & \\
\hline 10 & $\begin{array}{l}\text { Hamida } \\
\mathrm{h}\end{array}$ & $\begin{array}{l}\text { Desa } \\
\text { Palimban } \\
\text { g Sari }\end{array}$ & $\begin{array}{l}\text { Haur } \\
\text { Gading }\end{array}$ & Dikurung \\
\hline 11 & Galuh & $\begin{array}{l}\text { Desa } \\
\text { Palimbag } \\
\text { an }\end{array}$ & $\begin{array}{l}\text { Haur } \\
\text { Gading }\end{array}$ & \\
\hline 12 & M Bagri & $\begin{array}{l}\text { Desa } \\
\text { Sungai } \\
\text { Turak } \\
\text { Dalam } \\
\end{array}$ & $\begin{array}{l}\text { Sungai } \\
\text { Turak }\end{array}$ & \\
\hline 13 & Fansyah & $\begin{array}{l}\text { Desa } \\
\text { Padang } \\
\text { Besar } \\
\text { Hulu } \\
\end{array}$ & $\begin{array}{l}\text { Sungai } \\
\text { Turak }\end{array}$ & Dikurung \\
\hline 14 & $\begin{array}{l}\text { Marham } \\
\text { ah }\end{array}$ & $\begin{array}{l}\text { Desa } \\
\text { Pandawaa } \\
\mathrm{n}\end{array}$ & Guntung & $\begin{array}{l}\text { Dirantai } \\
\text { dan } \\
\text { dikurung }\end{array}$ \\
\hline
\end{tabular}

\begin{tabular}{|c|c|c|c|c|}
\hline 15 & Zainab & $\begin{array}{l}\text { Desa } \\
\text { Pandawaa } \\
\mathrm{n}\end{array}$ & Guntung & \\
\hline 16 & Ruslan & $\begin{array}{l}\text { Desa } \\
\text { Sungai } \\
\text { Karias }\end{array}$ & $\begin{array}{l}\text { Sungai } \\
\text { Karias }\end{array}$ & $\begin{array}{l}\text { Sudah } \\
\text { dirujuk }\end{array}$ \\
\hline 17 & Hendra & $\begin{array}{l}\text { Desa } \\
\text { Tambalan } \\
\text { gan }\end{array}$ & $\begin{array}{l}\text { Sungai } \\
\text { Karias }\end{array}$ & $\begin{array}{l}\text { Sudah } \\
\text { dirujuk }\end{array}$ \\
\hline 18 & Rusima & $\begin{array}{l}\text { Banua } \\
\text { Hanyar }\end{array}$ & $\begin{array}{l}\text { Pasar } \\
\text { Sabtu }\end{array}$ & $\begin{array}{l}\text { Dikurung } \\
\text { diruang } \\
\text { sempit }\end{array}$ \\
\hline 19 & Muhit & $\begin{array}{l}\text { Rantau } \\
\text { Bujur } \\
\text { Hulu }\end{array}$ & $\begin{array}{l}\text { Pasar } \\
\text { Sabtu }\end{array}$ & $\begin{array}{l}\text { Dikurung } \\
\text { dikamar }\end{array}$ \\
\hline 20 & $\begin{array}{l}\text { Fahrul } \\
\text { Raji }\end{array}$ & Galagah & $\begin{array}{l}\text { Pasar } \\
\text { Sabtu }\end{array}$ & \\
\hline 21 & $\begin{array}{l}\text { Bahrudi } \\
\text { n }\end{array}$ & $\begin{array}{l}\text { Pasar } \\
\text { Sabtu }\end{array}$ & $\begin{array}{l}\text { Pasar } \\
\text { Sabtu }\end{array}$ & $\begin{array}{l}\text { Dikurung } \\
\text { dan } \\
\text { dirantai }\end{array}$ \\
\hline 22 & $\begin{array}{l}\text { Abdurra } \\
\text { hman }\end{array}$ & Tapus & Alabio & Dipasung \\
\hline 23 & $\begin{array}{l}\text { Maimun } \\
\text { ah }\end{array}$ & $\begin{array}{l}\text { Desa } \\
\text { Bajawit }\end{array}$ & $\begin{array}{l}\text { Amuntai } \\
\text { Selatan }\end{array}$ & Dikurung \\
\hline 24 & Hartiah & $\begin{array}{l}\text { Telaga } \\
\text { Sari }\end{array}$ & $\begin{array}{l}\text { Amuntai } \\
\text { Selatan }\end{array}$ & $\begin{array}{l}\text { Dikurung } \\
\text { diruang } \\
\text { sempit }\end{array}$ \\
\hline 25 & $\begin{array}{l}\text { Fatmaw } \\
\text { ati }\end{array}$ & $\begin{array}{l}\text { Telaga } \\
\text { Hanyar }\end{array}$ & $\begin{array}{l}\text { Amuntai } \\
\text { Selatan }\end{array}$ & Dikurung \\
\hline 26 & Aminah & Jumba & $\begin{array}{l}\text { Amuntai } \\
\text { Selatan }\end{array}$ & $\begin{array}{l}\text { Dikurung } \\
\text { dan } \\
\text { dirantai }\end{array}$ \\
\hline 27 & Mariah & $\begin{array}{l}\text { Teluk } \\
\text { Paring }\end{array}$ & $\begin{array}{l}\text { Amuntai } \\
\text { Selatan }\end{array}$ & $\begin{array}{l}\text { Dikurung } \\
\text { diruang } \\
\text { sempit }\end{array}$ \\
\hline 28 & $\begin{array}{l}\text { Zairulla } \\
\mathrm{h}\end{array}$ & Panyiuran & $\begin{array}{l}\text { Amuntai } \\
\text { Selatan }\end{array}$ & $\begin{array}{l}\text { Dikurung } \\
\text { diruang } \\
\text { sempit } \\
\end{array}$ \\
\hline 29 & $\begin{array}{l}\text { Taufikur } \\
\text { rahman }\end{array}$ & $\begin{array}{l}\text { Sungai } \\
\text { Baring }\end{array}$ & $\begin{array}{l}\text { Sungai } \\
\text { Malang }\end{array}$ & $\begin{array}{l}\text { Dirantai/d } \\
\text { ipasung }\end{array}$ \\
\hline 30 & Basri & Rantawan & $\begin{array}{l}\text { Sungai } \\
\text { Malang }\end{array}$ & $\begin{array}{l}\text { Dirantai } \\
\text { (sudah } \\
\text { dirujuk) }\end{array}$ \\
\hline 31 & $\begin{array}{l}\text { Supiann } \\
\text { or }\end{array}$ & $\begin{array}{l}\text { Desa } \\
\text { Harus }\end{array}$ & $\begin{array}{l}\text { Sungai } \\
\text { Malang }\end{array}$ & Dirantai \\
\hline 32 & Wahidah & $\begin{array}{l}\text { Sungai } \\
\text { Dikom }\end{array}$ & $\begin{array}{l}\text { Sungai } \\
\text { Malang }\end{array}$ & $\begin{array}{l}\text { Dikurung } \\
\text { (Putus } \\
\text { obat) }\end{array}$ \\
\hline
\end{tabular}

Sumber : Dinas Kesehatan Kab. HSU Tahun 2018

Berdasarakan data diatas dapat diketahui bahwa orang dengan gangguan jiwa yang dirantai dan dikurung cukup tinggi, dengan jumlah 32 orang dengan sebaran dibeberapa kecamatan yang ada dihulu sungai utara, dengan adanya pengurungan dan dirantai tanpa adanya pemeuhan hak orang dengan gangguan jiwa jelas 
bertentangan dengan Undang-Undang nomor 18 tahun 2014 tentang Kesehatan Jiwa, hak yang dimaksud tersebut adalah hak untuk mendapatkan pengobatan dan perawatan serta rehabilitasi guna memperoleh kesembuhan seutuhnya agar mereka dapat menjadi manusia produktif secara sosial dan ekonomis. Tujuan penelitian ini untuk menganalisis Implementasi pemenuhan Hak orang dengan gangguan jiwa serta faktor-faktor yang mempengaruhinya.

\section{METODE PENELITIAN}

Jenis Penelitian yang digunakan dalam penelitian ini adalah jenis Kualitatif. Diharapkan dengan jenis ini akan ditemukan makna yang tersembunyi dibalik obyek maupun subjek yang akan diteliti. Jenis Penelitian Kualitatif sebagai suatu konsep keseluruhan berupaya untuk mengungkapkan rahasia sesuatu, dilakukan dengan menghimpun informasi dalam keadaan sewajarnya.

Sumber data adalah tempat atau asal data yang diperoleh dan dipergunakan. Sumber data dalam penelitian ini adalah : Data primer merupakan data asli yang memuat informasi atau data yang langsung diperoleh dari Informan, Pemilihan informan dilakukan dengan cara purposive (bertujuan) yakni orang yang dianggap mengetahui permasalah tentang implementasi Pemenuhan Hak Orang dengan gangguan jiwa,Data Sekunder adalah data yang tidak langsung memberikan data kepada peneliti, misalnya penelitian harus melalui orang lain atau mencari melalui dokumen. Data ini diperoleh dengan menggunakan studi literatur yang dilakukan terhadap banyak buku dan diperoleh berdasarkan catatancatatan yang berhubungan dengan penelitian. Instrumen utama dalam penelitian ini adalah peneliti itu sendiri, dimana peneliti merupakan alat pencari informasi, menilai keadan/tindakan dan mengambil keputusan dalam usaha pengumpulan data. Sebagai alat bantu dalam pengumpulan data, digunakan pula buku catatan, kamera untuk merekam gambar-gambar selama proses penelitian berlangsung, hanpone perekam untuk merekam kegiatan selama proses berlangsung.

Teknik pengumpulan data, Pengumpulan data Primer dilakukan dengan dua cara, yaitu Wawancara mendalam (indepth Interview) dan observasi lapangan. digunakan pula data sekunder yang pengumpulan dilakukan melalui kajian pustaka, sumber tertulis seperti buku, artikel, dokumen, dan lainlain yang masih ada relevansinya dengan bidang kaji penelitian. 
Analisis data dalam penelitian Kualitatif bersifat induktif dimana data yang diperoleh akan dianalisasi dan dikembangkan menjadi sebuah asumsi dasar penelitian, kemudian data-data lain terus dikumpulkan dan ditarik kesimpulan. Analisis data dalam penelitian ini menggunakan model Miles and Huberman dalam Sugiyono (2014:91) Data-data yang dikumpulkan dianalisis melalui beberapa tahapan yaitu data reduction, data display dan conclusion drawing/verification sehingga dapat diambil suatu kesimpulan.

\section{HASIL DAN PEMBAHASAN}

Setiap Kebijakan yang dikeluarkan atau ditetapkan oleh pemerintah pasti memiliki tujuan, tujuan pembuatan kebijakan publik pada dasarnya untuk mewujudkan ketertiban dalam masyarakat, melindungi hak-hak masyarakat, mewujudkan ketentraman dan kedamaian dalam masyarakat dan mewujudkan kesejahteraan masyarakat.

Undang-undag Nomor 18 Tahun 2014 tentang kesehatan jiwa, bertujuan untuk, menjamin setiap orang dapat mencapaikualitas hidup yang baik, menikmati kehidupan kejiwaan yang sehat, bebas dari ketakutan, tekanan, dan gangguan lain yang dapat mengganggu kesehatan jiwa; menjamin setiap orang dapat mengembangkan berbagai potensi kecerdasarn; memberikan perlindungan dan menjamin layanan kesehatan jiwa bagi orang dengan masalah kejiwaan (ODMK) dan orang dengan gangguan Jiwa (ODGJ) berdasarkan hak asasi manusia; memberikan pelayanan kesehatan secara integrasi, komprehensif, dan berkesinambungan melalui upaya promotif, preventif, kuratif, dan rehabilitatif bagi ODMK dan ODGJ; menjamin ketersediaan dan keterjangkauan sumber daya dalam upaya kesehatan jiwa; meningkatkan mutu Upaya kesehatan jiwa sesuai dengan perkembangan ilmu pengetahuan dan teknologi dan memberikan kesempatan kepada ODMK dan ODGJ untuk mendapat memperoleh haknya sebagai Warga Negara Indonesia.

\section{Ukuran dan Tujuan Kebijakan}

Kinerja implementasi kebijakan dapat diukur tingkat keberhasilan jika ukuran dan tujuan dari kebijakan memang realitis dengan sosio-kultur yang mengada di level pelaksana kebijakan. Ketika ukuran kebijakan atau tujuan kebijakan terlalu ideal (bahkan terlalu utopis) untuk dilaksanakan di level warga, maka agak sulit memang merealisasikan kebijakan publik hingga titik yang dapat dikatakan berhasil. 
Ukuran dasar kebijakan pelayanan pemenuhan hak orang dengan gangguan jiwa mengacu pada landasan hukum yang telah ditetapkan oleh pemerintah yang meliputi : 1 . Undang- Undang Nomor 39 Tahun 1999 tentang Hak Asasi Manusia, 2. Undang-Undang Republik Indonesia Nomor 36 Tahun 2009 Tentang Kesehatan, 3. Undang-Undang Republik Indonesia Nomor 18 Tahun 2014 Tentang Kesehatan Jiwa..

Berdasarkan hasil yang diperoleh dari informan, pada dasarnya semua sudah mengetahui tentang pemenuhan hak asasi manusia, terutama pemenuhan hak orang dengan gangguan jiwa, hal ini selaras dengan teori Van meter dan Van Horn yang menyatakan bahwa pemahaman pelaksana terhadap ukuran dn tujuan kebijakan mementukan keberhasilan proses implementasi kebeijakan.

\section{Sumber daya}

Keberhasilan proses implementasi kebijakan sangat tergantung dari kemampuan memanfaatkan sumberdaya yang tersedia.

Sumber daya manusia (staff) belum sepenuhya optimal dalam menjalankan implementasi kebijakan pemenuhan hak orang dengan gangguan jiwa salah satunya disebabkan oleh sumber daya yang belum mencukupi, memadai ataupun tidak kompeten dibidangnya Sarana Prasaran belum mencukupi dalam menjalankan pelayanan rehabilitasi kesehatan jiwa,

Sumber dana belum mencukupi untuk menjalakan berbagai program layanan rehabilitasi yang diamanatkan Undang-Undang Nomor 18 tahun 2014 tentang kesehatan jiwa.

\section{Karakteristik Agen Pelaksana}

Pusat perhatian pada agen pelaksana meliputi organisasi formal dan organisasi informal yang akan terlibat pengimplemntasian kebijakan publik. Hal ini sangat penting karena kinerja implementasi kebijakan (Publik) akan sangat banyak dipengaruhi oleh ciriciri yang tepat serta cocok dengan para agen pelaksananya.

Van mater dan Van Horn, dalam mengimplementasikan suatu program, karakteristik dari pelaksana kebijakan harus berkarakteristik keras dan ketat pada aturan serta taat pada sanksi hukum yang berlaku. Terdapat beberapa peraturan mekanisme yang terdapat pada Dinas Kesehatan Kabupaten Hulu Sungai Utara dalam upaya mendukung kebijakan pemenuhan hak orang dengan gangguan jiwa. 


\section{Komunikasi Antarorganisasi dan} Aktivitas Pelaksana.

Koordinasi merupakan mekanisme yang ampuh dalam implementasi kebijakan publik. Semakin baik koordinasi komunikasi diantara pihakpihak yang terlibat dalam suatu proses implementasi, maka asumsi kesalahan-kesalahan akan sangat kecil unutk terjadi dan begitu pula sebaliknya.

Untuk mempermudah penyelenggaran pelayanan kesehatan jiwa Dinas Kesehatan memiliki program rapat yang diadakan oleh Puskesmas ke Dinas Kesehatan pertriwulan sekali, dan Rapat yang diadakan oleh Dinas Kesehatan ke Puskesmas satu tahun sekali maupun dengan pihak rumah sakit daerah. Dengan pembahasan berbagai macam permasalahan kesehatan.

\section{Sikap/Kecendrungan (Disposition)} para Pelaksana.

Sikap penerimaan atau penolaksan dari (agen) pelaksana akan sangat banyak mempengaruhi keberhasilan atau tidaknya kinerja implementasi kebijakan publik. Hal ini sangat mungkin terjadi oleh karena kebijakan yang dilaksanakan bukanlah hasil formulasi warga setempat yang mengenal betul persoalan dan permasalahan yang mereka rasakan.

Para pelaksana kebijakan yang berkenan dengan pemenuhan Hak orang dengan gangguan jiwa telah mengetahui dan memahami standar dan tujuan dari kebijakan kesehatan jiwa, namun pada prakteknya pemahaman tersebut pemahaman tersebut hanya dilaksanakan oleh beberapa orang saja, artinya para pelaksanasendiri punya sudut pandang yang berbeda-beda,

Sikap penerima atau penolakan dari segi pelaksanaan kebijakan sangat mempegaruhi keberhasilan atau kegagaln implementasi kebijakan. Hal ini sangat mungkin terjadi katena kebijakan yang dilaksanakan bukankan hasil meteka rasakan, tetapi kebijakan publuk biayang bersifat top dwon yang sangat mungkin para pengambil keputusan tidak mengetahui bahwa tak mampu menyentuh kebutuhan, keinginan atau permasalhan yang diselesaikan.

\section{Lingkungan Ekonomi,Sosial, dan Politik}

Hal terakhir yang perlu juga diperhatikan guna menilai kinerja 
implementasi publik dalam persektif yang ditawarkan oleh Van Metter dan Van Horn adalah, sejauhmana lingkungan eksternal turut mendorong keberhasilan kebijkan publik yang telah ditetapkan. Lingkungan sosial, ekonomi, dan politik yang tidak kondusif dapat menjadi biang keladi dari kegagalan kinerja implementasi kebijakan. Karena itu, upaya untuk mengimplementasikan kebijakan harus pula memperhatikan kekondusifan kondisi lingkungan eksternal.

\section{a. Lingkungan Ekonomi}

Linkungan ekonomi adalah kondisi ekonomi diwilayah sekitar, kondisi ekonomi memiliki dampak yang kuat terhadap pemenuhan hak orang dengan gangguan jiwa.

Implementasi Pemenuhan hak orang dengan gangguan jiwa yang berkaitan dengan lingkungan ekonomi diketahui bahwa lingkungan ekonomi keluarga orang dengan gangguan jiwa sebagian besar berada pada garis ekonomi ke bawah. Hal ini sangat berpengaruh terhadap program perbaikan kejiwaan, apabila masyarakat sejahtera maka dimungkinkan masalah kejiwaan bisa diatasi.

\section{b. Lingkungan Sosial}

Lingkungan sosial juga disebut dengan konteks sosiokultur, kebiasaan masyarat sangat mempengaruhi keberhasilan kebijakan.

Implementasi pemenuhan hak orang dengan gangguan jiwa di Kabupaten Hulu Sungai Utara yang berkaitan dengan lingkungan Sosial diketahui keluarga merasa malu apabila ada salah seorang keluarga yang terkena gangguan jiwa, sehingga diberlakukan penangan dikurung maupun dirantai sehingga persepsinya tidak mengganggu orang lain.

\section{c. Lingkungan Politik}

Lingkungan politik adalah hukum, instansi pemerintah dan kelompok penekan yang mempengaruhi dan membatasi organisasi dan individu dalam menjalankan pemenuhan hak orang dengan gangguan jiwa.

Implementasi pemenuhan hak orang dengan gangguan jiwa yang berkaitan dengan lingkungan politik diketahui bahwa perhatian dari instansi yang lebih tinggi hanya 
dilakukan pada saat acara kegiatan yang dilakukan oleh Dinas Kesehatan, akan tetapi acara rutinitas perhatian terhadap pemenuhan hak orang dengan gangguan jiwa belum maksimal dilaksanakan.

Faktor-faktor

Mempengaruhi

Implementasi

Pemenuhan Hak Orang Dengan

Gangguan Jiwa di Kabupaten Hulu Sungai Utara :

\section{Sumber Daya}

Sumber daya manusia yang belum sepenuhnya mencukupi dalam menjalankan pelayanan kesehatan jiwa dimana pada Rumah Sakit Umum daerah hanya terdapat 1 doktor yang menangani masalah kejiwaan, faktor yang berkaitan dengan sumber daya juga, sumber daya fasilitas dan dana yang belum sepenuhnya memadai dan mencukupi.

\section{Lingkungan Ekonomi,Sosial, dan Politik}

Pemenuhan hak orang dengan gangguan jiwa yang berkaitan dengan lingkungan ekonomi diketahui bahwa lingkungan ekonomi keluarga orang dengan gangguan jiwa sebagian besar berada pada garis ekonomi ke bawah. Hal ini sangat berpengaruh terhadap program perbaikan kejiwaan, lingkungan Sosial diketahui keluarga merasa malu apabila ada salah seorang keluarga yang terkena gangguan jiwa, sehingga diberlakukan penangan dikurung maupun dirantai sehingga persepsinya tidak mengganggu orang lain. lingkungan politik diketahui bahwa perhatian dari instansi yang lebih tinggi hanya dilakukan pada saat acara kegiatan yang dilakukan oleh Dinas Kesehatan, akan tetapi acara rutinitas perhatian terhadap pemenuhan hak orang dengan gangguan jiwa belum maksimal dilaksanakan.

\section{PENUTUP}

Berdasarkan hasil penelitian yang telah dilakukan dapat disimpulkan bahwa :

1. Impementasi Pemenuhan Hak Orang dengan gangguan jiwa belum sepenuhnya berjalan dengan baik, hal tersebut diliat dari Sumber daya untuk menjalakan pelayanan kesehatan jiwa belum sepenuhnya memadai, dan masih terdapatnya permasalah yang 
berkaitan dengan lingkungan ekonomi, sosial dan politik.

2. Faktor yang mempengaruhi Implementasi Pemenuhan Hak Orang Dengan Gangguan Jiwa di Kabupaten Hulu Sungai Utara dipengaruhi oleh beberapa faktor ;

1. Sumber daya

2. Lingkungan Ekonomi, Sosial dan Politik

\section{SARAN}

Berdasarkan kesimpulan penelitian, maka dapat diberikan saran sebagai berikut :

1. Bagi Pemerintah Daerah Kabupaten Hulu Sungai Utara perlu memperhatikan sumber daya dalam pemenuhan hak orang dengan gangguan jiwa, sumber daya yang dimaksud Sumber daya manusia, Sarana Prasarana dan Dana, sehingga kegiatan pelayanan kesehatan gangguan jiwa dapat berjalan dengan maksimal. dan bagi Instansi Terkait yang menjalankan pelayanan kesehatan jiwa perlu melakukan program penyuluhan, sosialisasi yang bertujuan merubah anggapan yang menganggap orang dengan gangguan jiwa selalu dikurung dan dirantai.
2. Bagi Masyarakat perlu mendukung kebijakan Pemerintah dalam pemenuhan Hak Orang dengan gangguan jiwa dengan memberikan kesempatan rehabilisasi dan pengobatan tanpa melanggar hak orang dengan gangguan jiwa dengan merantai maupun mengurung orang dengan gangguan jiwa.

\section{DAFTAR PUSTAKA}

Abdul Wahab,2008,Pengantar Analisis Kebijakan Publik.Hak Terbit Pada UMM Press

Agustino,Leo,2008,Dasar Dasar Kebijakan Publik. Bandung :Alfabeta

Ali,Faried, et al.,2012, Studi Analisis Kebijakan,Bandung, PT Refika Aditama

Bugin,Burhan,2007.Penelitian

Kualitatif,Komunikasi,Ekonomi Kebijakan Publik

dan Ilmu Sosial lainnya, Jakarta, Prenada Media Group

Danim Sudarwan,2002,Menjadi Penelitian Kualitatif,Bandung,Cv Pustaka Setia 
Denhardt V. Janet, Denhart B.Robert,

2013,Pelayanan Publik Baru,

KreasiWacana

Dunn,William N,2003,Pengantar Analisis

Kebijakan Publik,Yogyakarta,Gadjah

Mada University Press

Fischer,Frank, et al.,2015. Handbook Analisis Kebijakan Publik, Teori, Politik dan Metode, Bandung, Nusa Media

Kartono, Kartini. 2014. Patologi Sosial 3 : Gangguan-gangguan kejiwaan. Jakarta: Raja Grafindo Persada

\section{Narbuko,Cholid} dan

Achmadi,Abu,2007,Metode Penelitian, Jakarta:Bumi Aksara

Muhith , Abdul. 2015. Pendidikan keperawatan jiwa. Yogyakarta : Andi

Riyadi, Sujono \& Purwanto, Teguh. 2009. Asuhan Keperwata Jiwa. Yogyakarta :

Graha Ilmu

Simanjuntak, Julianto.2008. Konseling Gangguan Jiwa \& Okultisme. Jakarta :

Gramedia Pustaka Utama

Siswanto. 2007. Kesehatan mental,konsep, cakupan dan perkembanganya.
Yogyakarta : Andi

Sugiyono. 2013. Metode Penelitian Kuantitatif, Kualitatif, dan R\&D.

Bandung:Alfabeta.

Satiri,Djam'an dan Komariah,Aan,2014.

Metodologi Penelitian Kualitatif

Bandung, Cv Alfabeta

\section{Sumber lain-lain}

Undang-Undang Dasar Negara Republik Indonesia Tahun 1945

Undang-undang Republik Indonesia Nomor 39 Tahun 1999 Tentang Hak Asasi Manusia

Undang-undang Republik Indonesia Nomor 36 Tahun 2009 tentang Kesehatan

Undang-Undang Republik Indonesia Nomor 18 Tahun 2014 Tentang Kesehatan Jiwa

Peraturan Menteri Kesehatan Republik Indonesia Nomor 49 Tahun 2016 Tentang Pedoman Teknis Pengorganisasian Dinas Kesehatan Provinsi Dan Kabupaten/Kota 